\title{
Predictors of School Safety Awareness Among Malaysian Primary School Teachers
}

Ssekamanya, S.A.

Mastura Badzis

Khamsiah Ismail

Dayang Shuzaidah Bt Abduludin

International Islamic University Malaysia

\begin{abstract}
With rising incidents of school violence worldwide, educators and researchers are trying to understand and find ways to enhance the safety of children at school. The purpose of this study was to investigate the extent to which the demographic variables of gender, age, length of service, position, academic qualification, and school location predicted teachers' awareness about school safety practices in Malaysian primary schools. A stratified random sample of 380 teachers was selected in the central Malaysian states of Kuala Lumpur and Selangor. Multiple regression analysis revealed that none of the factors was a good predictor of awareness about school safety training, delivery methods of school safety information, and available school safety programs. Awareness about school safety activities was significantly predicted by school location (whether the school was located in a rural or urban area). While these results may reflect a general lack of awareness about school safety among primary school teachers in the selected locations, a national study needs to be conducted for the whole country.
\end{abstract}

Keywords: School Safety Awareness, Predictors of School Safety, Multiple Regression analysis, Malaysian Primary Schools

\section{Introduction}

The world has recently witnessed increasing incidences of school violence. In Malaysia, UNICEF Malaysia reported that $16 \%$ of Malaysian kids were out of school due to violence (UNICEF Malaysia, 2014). Violence in school includes bullying and others. Moreover, 8,015 arrests that were made in 2014, including 12 years-old children involved in criminal activities such as drug abuse, gambling and social problems. In 2013, 7,816 juvenile cases were recorded, mostly involving school students (Royal Malaysian Police Statistics, 2014).

Among the public, there is a growing perception that schools are not as safe as they were before (The Star, 2000). A review of the literature in Malaysia reveals a dearth of in-depth research on the topic of this study. Nevertheless, one study on "Gangsterism in day school" done by the Education Ministry indicates that 30\% of secondary schools in Malaysia are threatened by gangsters. Out of 1641 schools, 459 have been classified as high-risk with Penang being the worst affected state (Simrit Kaur, 2000).

\section{The Need for School Safety}

The idea of a positive and safe learning environment is necessary for students to learn (Reeves, Kanan \& Plog, 2010). A well-functioning school is not only a school that promotes learning, but also attends to safety and teaches socially appropriate behaviour. Reeves, Kanan \& Plog (2010) also listed safe school characteristics including balance between physical and psychological safety to create and maintain safe and positive environment.

Giving another concept on school safety, Mastura (2013) defined safety as "the behaviours and practices that protect children and adults form risk or injury" (p.11). She suggested safety of young children is of special concern because they have no sense of danger and the consequences of their action. Mastura (2013) also affirmed that school's environments or school's climate or have a direct impact on students' well-being. Similar concept on school's environment have effect on 
students' well-being found in Simmons (1999) whom defined safety as a concern about physical or emotional security. It is a preference for social and physical settings that provide protection and minimize the chances of being attack or hurt.

As from the school's context, safety is perceived as a school environment where children are safe from all types of hazards and risk (UNESCO, 2012). Carbino (2010) set out a safe school is one, where teachers can teach and students can learn in a warm, encouraging, and nurturing environment without the threat and resulting fear of violence occurring at any moment. This is also to say that safe, caring, participatory and responsive school climate fosters greater attachment to school and provides the optimal foundation for social, emotional and academic learning (Osterman, 2000; Blum, McNeely \& Rinehart, 2002).

Although there is not one list of factors that shape the quality and character of school's life, virtually all researchers agree that there are four major areas that clearly shape school climate: safety, relationships, teaching and learning, and the (external) environment. Over the last three decades, educators and researchers have recognized that complex sets of elements make up school climate. There is not one commonly accepted "list" of the essential dimensions that colour and shape school climate. A review of research, practitioner, and scholarly writings suggests that there are four major aspects of school life that colour and shape school climate including safety, teaching and learning, relationships and environmentalstructural (Cohen, 2006; Freiberg, 1999).

A growing body of research has indicated that a positive school climate is a critical dimension linked to effective risk prevention and health promotion efforts as well as teaching and learning (Cohen, 2001; Juvonen, Le Kaganoff, Augustine \& Constant, 2004; Najaka, Gottfredson \& Wilson, 2002; Wang, Heartel \& Walberg, 1993). Previous research also found a safe, caring, participatory and responsive school climate fosters greater attachment to school and provides the optimal foundation for social, emotional and academic learning (Blum, McNeely \& Rinehart, 2002; Osterman, 2000).

The search for tools of psychological resistance and the conditions that reduce threats and mitigate the risk of safety inhibition is not only a social need in modern conditions but also the task of special studies. In the psychological context the search for tools and conditions for studying the perception, cognition and assessment of the educational environment for the development of students and teachers is progressive.

Teaching and learning cannot take place in an unsafe environment. The art of creating a peaceful school environment poses great challenges to school management. It is stipulated in the Bill of Right (Act No.108 of 1996), Section [24]) that every person has the right to an environment that is not detrimental to his health or well-being. This right also applies to learners, and in principle protects them from being exposed to harmful environments, including the school. The educator, in addition to this duty to teach and educate, is also required to provide education, physical and mental safety to learners (Oosthuzen, et al, 1994).

Further, many researchers agree that physical and psychosocial environment is significantly correlated in which it gives impact on students' achievement and well-being, affect teaching (American Association of University Women \& Lewis Harris Associates, 1993; American Association of University Women \& Lewis Harris Associates, 2001; Center for Mental Health in Schools at UCLA, 2004; Prothrow-Stith \& Quaday, 1995) and creates barriers to learning (Edmondson et.al, 2009).

\section{The Role of Teachers' Perceptions}

Teachers are on the frontlines when it comes to issues of school safety. They interact with the children on a day-to-day basis and they are the first to know of any acts of violence at school. Brand, Felner, Seitsinger, Burns, and Bolton, (2008) found in a large-scale study that teachers were not only acutely aware of what was going on in terms of school safety, but also that their perceptions positively correlated with students' perceptions, behaviors, and outcomes.

McElearney \& Stead (2011) studied 50 participants including teachers, classroom assistants and allied health professional working in mainstream primary and special schools in the Ballymena District Council area. Focus group discussion was conducted to explore the views and experience of participants and valuable insight into the barriers and facilitative factors to teach "keeping safe" message in primary schools in Northern Ireland. Teachers reported varied states of readiness with the development and teaching of "keeping safe" message through preventive education in primary schools. Teachers and other school staff also have varied practices in how they currently taught "keeping safe" message. The special school sector 
reported teaching more sensitive message for example appropriate and inappropriate touch. In contrary with teachers from integrated and Catholic Maintained schools, teaching are focus on accident, prevention, internet safety, bullying and stranger danger.

The study also found that teachers varied in their attitudes on expressing their role in safeguarding the welfare of children in schools. Minority of participants expressed reluctance for schools and teachers to take on the responsibility for teaching keeping safe message. However, all teachers, classroom assistants and allied health professionals working in special school acknowledge that they had a role to play in teaching keeping safe messages to children.

In addition to the findings, participants highlighted the opportunity presented by the revised curriculum to embed the teaching of keeping safe message within primary schools. They were clear that any approach to development in this area should include integration across all aspects of the school, the role of the teacher and the training, development and support needs of school staff in teaching keeping safe message (Stephenson, P., McElearney, A., \& Stead, J. 2011).

\section{The Present Study}

The previous studies discussed in the foregoing paragraphs, as well as other researchers, including Douglas, Warwick, Kemp, and Whitty, G. (1997); Maxwell (2000); Bradshaw, Sawyer, and O'Brennan (2007); Astor, and Meyer (1999); Stockdale, Saidou Hangaduambo, David Duys, Karl Larson, and Paul D. Sarvela (2002); Behre, Astor, and Meyer, (2001); Price and Everett (1997); and Cothran, and Ennis, (1997), have found teachers' perceptions to play a major role in their commitment to creating a positive school climate and in promoting safe school practices. What is not generally highlighted in these studies however, is the extent to which teachers' perceptions and actions could be influenced by important background variables. Drawing from teacher behavior research, we hypothesized that teachers' perceptions about school safety practices could be influenced by the key demographic variables of gender, age, length of service, position, academic qualification, and school location. As Malaysia is grappling with the increasing incidences of school safety breaches, we hoped that this could add important insights on future strategies for dealing with this problem.

\section{Method}

This study was conducted using the survey method. A stratified random sample of 378 teachers was selected in the central Malaysian states of Kuala Lumpur and Selangor. A survey instrument was created based on the work of Steve Balen, John Dively, Ronald Ellis, Sanford Farkash, Marilyn Holt, John Hunt, Micheal Kotner, Caroll Phelps, Peter Renfroe, Joseph Saban, Lisa Stewart and Don Strom (1999). In this analysis, 26 items were utilised, divided into four dimensions as shown in Table 1. The reliability coefficients ranged between .35 and .886 .

\section{Results and Discussion}

\section{Teachers' Perceptions of School Safety Practices}

In general, the sample had average perceptions about school safety practices in Malaysian schools. On a 5-point likert scale, the mean responses ranged between 2.3 (awareness of delivery methods) and 2.5 (awareness of training programs).

\section{Predictors of Teachers' Perceptions about school Safety}

In order to test the hypothesis regarding the demographic predictors of teachers' awareness about school safety practices in Malaysian primary schools, the researchers used multiple regression analysis (MRA). Below is a summary of the results of the regression analysis. 
Awareness of Training Programs. The regression equation was not significant $(F(8,370)=1.09, p>.05)$ with an $R^{2}$ of .023 . None of the independent variables (gender, age, length of service, position, academic qualification, and school location) was a significant predictor of teachers' awareness of school safety training programs.

Awareness of Delivery Methods. The regression equation was not significant $(F(8,370)=1.57, p>.05)$ with an $R^{2}$ of .033 . None of the independent variables (gender, age, length of service, position, academic qualification, and school location) was a significant predictor of teachers' awareness of school safety delivery methods.

Awareness of Safety Programs. The regression equation was not significant $(F(8,370)=1.57, p>.05)$ with an $R^{2}$ of .035 . None of the independent variables (gender, age, length of service, position, academic qualification, and school location) was a significant predictor of teachers' awareness of school safety programs.

Awareness of Safety Activities. Standard Multiple regression was used to test the demographic predictors of Malaysian teachers' awareness of safety activities at their respective schools. Overall, the model significantly predicted teachers' awareness of safety activities, $R^{2}=.048, R^{2} a d j=.027, F(8,370)=2.335, p<.05$. This model accounts for about $5 \%$ of the variance in Social Adjustment (a small effect according to Cohen, 1988). Of the six independent variables only School Location significantly contributed to the model (Table 2).

While we would predict variables like gender to play a major role, it was quite surprising to find that none of them was actually significant. This shows that teachers' perceptions on most aspects of safety were quite similar. The only difference we found was regarding their awareness about school safety activities where location emerged as a significant predictor. Teachers from rural areas had slightly lower means for perceptions of school safety activities (mean=2.5) compared to their urban counterparts (mean=2.7). In general, however, the overall perceptions about school safety practices were low, indicating that more concrete steps need to be taken to reassure the teachers.

\section{Conclusion}

What is presented here is a preliminary analysis of results from a large study. While these results indicate a low rating for perceptions of school safety practices among teachers, they are not conclusive. Further research needs to be conducted to fully understand the mechanism involved.

\section{References}

[1] Astor, R. A., \& Meyer, H. A. (1999). Where girls and women won't go: Female students', teachers', and social workers' views of school safety. Children \& Schools, 21(4), 201-219.

[2] Badzis, M. (2013). Study guide: HBEC 4103 Safety, health and nutrition in early childhood education.

[3] Behre, W. J., Astor, R. A., \& Meyer, H. A. (2001). Elementary-and middle-school teachers' reasoning about intervening in school violence: An examination of violence-prone school subcontexts. Journal of Moral Education, 30(2), 131-153.

[4] Blum, R. W., McNeely, C., Nonnemaker, J., Fischhoff, B., Nightingale, E. O., \& lannotta, J. G. (2001). Vulnerability, risk, and protection. Adolescent risk and vulnerability: Concepts and measurement, 50-72.

[5] Bradshaw, C. P., Sawyer, A. L., \& O'Brennan, L. M. (2007). Bullying and peer victimization at school: Perceptual differences between students and school staff. School psychology review, 36(3), 361.

[6] Brand, S., Felner, R., Shim, M., Seitsinger, A., \& Dumas, T. (2003). Middle school improvement and reform: Development and validation of a school-level assessment of climate, cultural pluralism, and school safety. Journal of Educational Psychology, 95(3), 570-588. doi:10.1037/0022-0663.95.3.570

[7] Brand, S., Felner, R. D., Seitsinger, A., Burns, A., \& Bolton, N. (2008). A large scale study of the assessment of the social environment of middle and secondary schools: The validity and utility of teachers' ratings of school 
climate, cultural pluralism, and safety problems for understanding school effects and school improvement. Journal of School Psychology, 46(5), 507-535.

[8] Brown, R. P., Osterman, L. L., \& Barnes, C. D. (2009). School violence and the culture of honor

[9] Carbino,V. (2010). You can hide, watch, or run but you better be not snitch: A study of student perception of school safety at an urban high school (Doctoral dissertation, University of California). Available from Proquest Dissertations and Theses database. (UMI No. 3419884)

[10] Cothran, D. J., \& Ennis, C. D. (1997). Students' and teachers' perceptions of conflict and power. Teaching and Teacher Education, 13(5), 541-553.

[11] Douglas, N., Warwick, I., Kemp, S., \& Whitty, G. (1997). Playing It Safe: Responses of secondary school teachers to lesbian, gay and bisexual pupils, bullying, Hiv and AIDS education and Section 28. Health and Education Research Unit. Institute of Education. University of London, London.

[12] Edmondson, L., Fetro, J., Drolet, J. C., \& Ritzel, D. O. (2004). perceptions of physical and psychosocial, (256), $1-10$.

[13] Edmondson, L., \& Hoover, J. (2008). Process evaluation of a bullying prevention program: A public schoolcounty health partnership. Reclaiming Children and Youth, 16(4), 25.

[14] Freiberg, H. J., \& Stein, T. A. (1999). Measuring, improving and sustaining healthy learning environments. School climate: Measuring, improving and sustaining healthy learning environments, 11-29.

[15] Gottfredson, D. C., Wilson, D. B., \& Najaka, S. S. (2002). 4 School-based crime prevention. Evidence-based crime prevention, 56.

[16] Juvonen, J., Le, V. N., Kaganoff, T., Augustine, C. H., \& Constant, L. (2004).Focus on the wonder years: Challenges facing the American middle school. Rand Corporation.

[17] Kaur, S. (2009). Social Safety Nets, Economic Freedom and Public Policy.

[18] Maxwell, L. E. (2000). A safe and welcoming school: What students, teachers, and parents think. Journal of Architectural and Planning Research, 271-282.

[19] McElearney, A., Scott, J., Adamson, G., Turtle, K., McBride, O., \& Stephenson, P. (2011). Establishing the need to teach" Keeping Safe" messages in primary schools in Northern Ireland: what do children currently know and understand?.

[20] Price, J. H., \& Everett, S. A. (1997). Teachers' Perceptions of Violence in the Public Schools: The Metlife Survey. American Journal of Health Behavior,21(3), 178-86.

[21] Reeves, M. A., Kanan, L. M., \& Plog, A. E. (2010). Comprehensive Planning for Safe Learning Environments: A School Professional's Guide to Integrating Physical and Psychological Safety, Prevention Through Recovery. Taylor \& Francis.

[22] Stockdale, Margaret S., Saidou Hangaduambo, David Duys, Karl Larson, and Paul D. Sarvela. (2002) "Rural elementary students', parents', and teachers' perceptions of bullying." American Journal of Health Behavior 26, no. 4 (2002): 266-277.

Tables

Table 1.

Dimensions and reliability of the instrument 


\begin{tabular}{lll}
\hline Awareness of Training Programs & 7 & .88 \\
Awareness of Delivery Methods & 3 & .35 \\
Awareness of Safety Programs & 3 & .72 \\
Awareness of Safety Activities & 3 & .886 \\
\hline
\end{tabular}

Table 2

Model coefficients for Awareness about School Safety Activities

\begin{tabular}{lllll}
\hline & $B$ & $\beta$ & $t$ & $p$ \\
\hline Gender & -.373 & -.062 & -1.181 & .238 \\
Age & -.282 & -.089 & -1.144 & .254 \\
Length of Service & -.025 & -.008 & -.105 & .916 \\
Position & -.044 & -.009 & -.158 & .874 \\
Acad. qualification & -.299 & -.064 & -.810 & .418 \\
School Location & 1.075 & .209 & 3.288 & .001 \\
\hline
\end{tabular}

